\title{
Prevalence and Associated Factors of Suboptimal Daily Peak Inspiratory Flow and Technique Misuse of Dry Powder Inhalers in Outpatients with Stable Chronic Airway Diseases
}

\begin{abstract}
Nan Ding, I,* Wei Zhang,,* Zhuo Wang,' Chong Bai, ${ }^{3}$ Qian $\mathrm{He},{ }^{4}$ Yuchao Dong, (D) ${ }^{3}$ Xiumin Feng, ${ }^{5}$ Jingxi Zhang, ${ }^{3}$ Shen Gao id '

'Department of Pharmacy, First Affiliated Hospital of Naval Medical University (Changhai Hospital), Shanghai, People's Republic of China; ${ }^{2}$ Department of Pharmacy, Shanghai Pulmonary Hospital, Tongji University School of Medicine, Shanghai, People's Republic of China; ${ }^{3}$ Department of Respiratory and Critical Care Medicine, First Affiliated Hospital of Naval Medical University (Changhai Hospital), Shanghai, People's Republic of China; ${ }^{4}$ Department of Health Statistics, Faculty of Health Service, Naval Medical University, Shanghai, People's Republic of China; ${ }^{5}$ Department of Respiratory and Critical Care Medicine, Changii Branch of First Affiliated Hospital of Xinjiang Medical University, Xinjiang, People's Republic of China
\end{abstract}

*These authors contributed equally to this work

Correspondence: Shen Gao

Department of Pharmacy, First Affiliated Hospital of Naval Medical University (Changhai Hospital), No. 168 Changhai Road, Shanghai, 200433, People's Republic of China

Tel +86(02I) 3 I I $6233 \mid$

Fax +86(02I)3II62304

Email liullk@I26.com

Jingxi Zhang

Department of Respiratory and Critical

Care Medicine, First Affiliated Hospital of

Naval Medical University (Changhai

Hospital), No. 168 Changhai Road, Shanghai,

200433, People's Republic of China

Email jingxizhang2000@।26.com
Purpose: The present study aimed to investigate the prevalence and associated factors of suboptimal daily peak inspiratory flow (PIF) and technical misuse of three commonly used dry powder inhalers (DPIs) in outpatients with stable chronic airway diseases.

Patients and Methods: Included in this study were 85 outpatients with stable asthma, chronic obstructive pulmonary disease (COPD), or asthma-COPD Overlap (ACO) and had previously used any of Turbuhaler $\left.{ }^{(}\right)$(TUR), Diskus ${ }^{\circledR}$ (DIS), HandiHaler ${ }^{\circledR}$ (HAN) between December 2018 and September 2019. The patient's daily PIF against the resistance of a specific DPI and operation technique was investigated by two pharmacists by using InCheck DIAL G16 and a checklist.

Results: Of the 85 patients, the proportion of patients with a suboptimal daily PIF and technical misuse was $38.8 \%$ and $65.9 \%$, respectively. In logistic regression, we observed that the factors that increase the risk for suboptimal daily PIF were age $(\mathrm{OR}=1.06)$ and combination with respiratory diseases $(\mathrm{OR}=6.59)$. The factor that decreases the risk for misuse was the higher education level (OR $=0.63$ ).

Conclusion: Even if patients have received training at the time of initial prescription, the standardization of the use of DPIs by patients in our center was still unoptimistic. Age and combined with respiratory diseases were associated with suboptimal PIF. Higher education level decreased the incidence of technique misuse.

Keywords: dry powder inhaler, inhalation technique, peak inspiratory flow rate, pharmacist, risk factors

\section{Introduction}

DPIs are common devices for carrying drugs for the treatment of asthma ${ }^{1}$ and chronic obstructive pulmonary disease (COPD), ${ }^{2}$ which are characterized by the patients' breath-driven delivery of drugs. Peak inspiratory flow rate (PIF) is an important factor to ensure sufficient deaggregation of the medication particles from the carrier particles to occur during an inhalation. ${ }^{3}$ However, some patients may not know or cannot achieve the ideal PIF. ${ }^{4}$ Besides, correct operating DPIs is also very important. However, current studies have revealed that misuse of the DPIs is very common in asthma and COPD patients ${ }^{5,6}$ Even patients who have been trained in operating procedures may have operational problems. Our center has always provided face-to-face education to patients who prescribe inhalers for the first time. 
However, we found that misuse of the device was common during follow-up. Moreover, fast and deep inhalation was not quantitatively evaluated before. In this study, we replaced the observation method with the measurement of PIF to quantitatively evaluate the "fast and deep" inhalation method. Combined with the checklist of operating steps, a complete assessment of the patient's use of DPIs was carried out. Few studies in mainland China have reported PIF measurement in patients using DPIs, except one assessment of the inspiratory ability in healthy children. ${ }^{7}$ Besides, we study the associated factors of suboptimal daily PIF and technical misuse of three commonly used DPIs including HandiHaler ${ }^{\circledR}$ (HAN), Turbuhaler ${ }^{\circledR}$ (TUB), and Diskus ${ }^{\circledR}$ (DIS) in adult patients with chronic airway diseases.

\section{Patients and Methods Study Participants and Design}

This study was conducted between Dec 2018 and Sep 2019 at the outpatient clinic of respiratory and critical care medicine of Changhai Hospital, a 2,000-bed teaching hospital in Shanghai, China. Initially recruited in this study were outpatients of both sexes who were diagnosed with COPD or ACO according to the Global Initiative for Chronic Obstructive Lung Disease (GOLD) criteria and Asthma according to the global initiative for asthma (GINA) guidelines and received treatment on the outpatient basis. Patients at least used one of the abovementioned three DPIs for at least two weeks. The exclusion criteria were as follows: patients whose conditions became acutely exacerbated during the previous one month, patients with a diagnosis of dementia, psychiatric disorders, Parkinson's disease. The flow chart of this research was shown in Figure 1. This study was approved by the Ethics Committee of Changhai Hospital (Ethical Committee Approval No.: CHEC2019-061) and conducted in accordance with the Declaration of Helsinki. Patients who met the screening criteria provided written informed consent after being fully informed of the study purpose and procedures.

\section{Data Collection}

Data collected by inquiring directly or consulting the patient's medical records and recorded the data within the most recent year $\left(\mathrm{FEV}_{1}, \mathrm{PEF}, \mathrm{FEV}_{1} \%\right.$ Predicted).

Demographic characteristics included age (years), sex, and education level (illiteracy/primary school/junior high school/high school/university and above). The clinical measures were: weight $(\mathrm{kg})$, body mass index $\left(\mathrm{kg} / \mathrm{m}^{2}\right)$; current smoking status (yes/no), smoking years, the number of smoking index [(the number of cigarettes smoked per day) multiplied by (the number of years of smoking)]; current with respiratory comorbidities (yes/no); the $\mathrm{FEV}_{1}$, PEF, $\mathrm{FEV}_{1} \%$ Predicted; the grade of dyspnea [measured with the modified British Medical Research Council (mMRC) scale], COPD assessment test $\left(\mathrm{CAT}^{\mathrm{TM}}\right)$, Asthma control test $\left(\mathrm{ACT}^{\mathrm{TM}}\right)$, degree of asthma control (grading of ACT scores).

\section{Daily PIF Measurement by in-Check Dial GI6}

The patient was required to simulate the daily inhalation process ("as if using your inhaler") by using InCheck Dial G16 (Clement-Clarke International Ltd, Harlow, UK), a hand-held inspiratory flow device that simulates different internal resistances of $\mathrm{DPIs}^{8}$ to evaluate daily PIF against the resistance of the specific DPI that the patient was currently using. HAN, TUR, and DIS respectively corresponded to the high, medium, and med-low resistance of the In-Check Dial instrument. We defined PIF as "below minimum" if his/her measured PIF below 20L/min for HAN, or below $30 \mathrm{~L} / \mathrm{min}$ for TUR or DIS. If PIF was below $30 \mathrm{~L} / \mathrm{min}$ for $\mathrm{HAN}$, or below $60 \mathrm{~L} / \mathrm{min}$ for TUR or DIS, we defined it as "suboptimal". For patients who used HAN with a daily PIF below 20L/min, pharmacists verbally asked whether they heard the capsule rattle (vibrate). The PIFs were measured three times and the maximum value was used to analyze whether the patient's daily PIF was in the appropriate range corresponding to the instrument.

\section{Assessment of Correct Use of the DPIs by a Self-Designed Checklist}

Patients were requested to demonstrate their use of the (drug-free) inhalers to evaluate the correctness of their inhalation technique by using a checklist jointly developed by the pharmacists and physicians according to the manufacturer's recommendations of the three DPIs (HAN, TUR, and DIS) and reports in the published literature. ${ }^{9}$ The specific evaluation steps are listed in Table 1. Among the steps, the step of "breathe out completely", "breathe in rapidly and deeply", "hold breath", "breathe normally after holding breath", and "repeat the inhalation if necessary" 


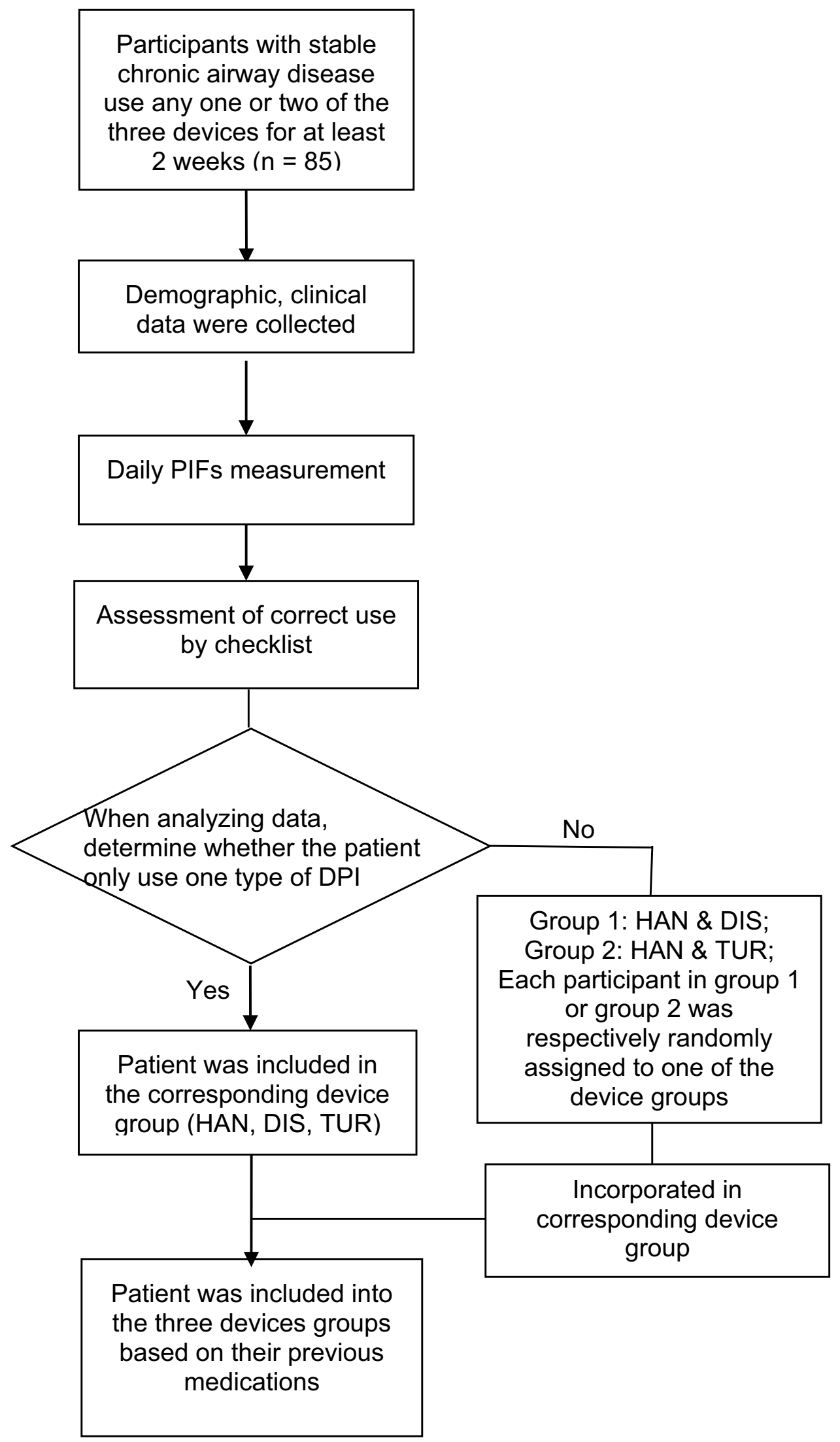

Figure I The research flow chart. 
Table I Checklist for the Technical Assessment of HAN/TUR/DIS Inhaler Use

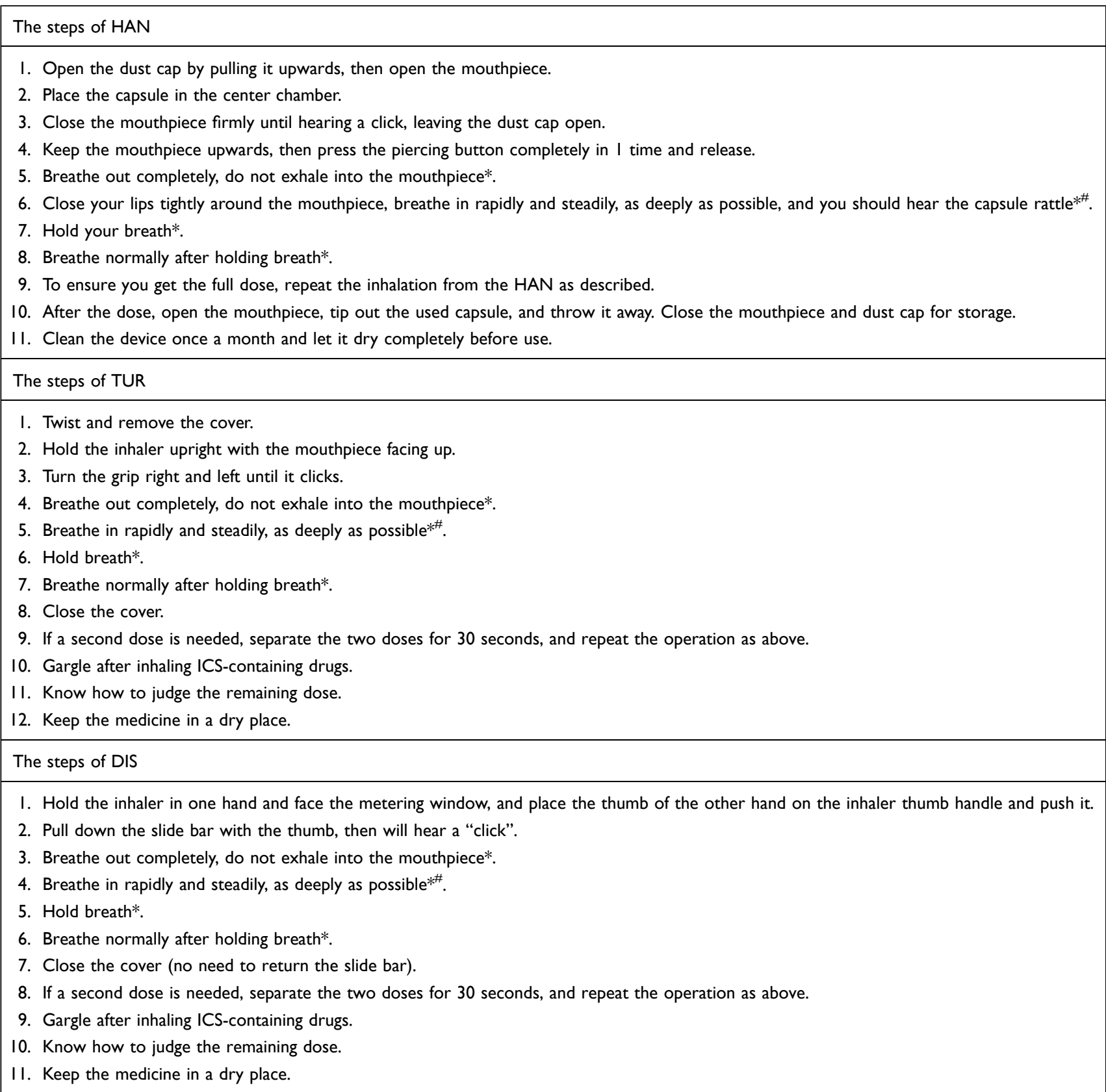

Notes: *These steps were the breathing-related steps. " Instead of using observation evaluation, but use peak flow rate evaluation by In-Check Dial.

Abbreviations: HAN, HandiHaler ${ }^{\circledR}$; TUR, Turbuhaler $^{\circledR}$; DIS, Diskus ${ }^{\circledR}$.

were the breathing-related steps. The step of "fast and deep inhalation" (the sixth step of HAN, the fifth step of TUR, and the fourth step of DIS) was not evaluated, but the measurement of PIF was used to replace it. Two experienced pharmacists independently evaluated the specific steps according to the checklist, and any wrong step was recorded as an error. Each missed step was also considered an error. Any disagreement between the two pharmacists would be solved by discussion.

\section{Statistical Analysis}

If the patient used one type of DPIs, the patient was included in the corresponding inhaler group. If the patient used two different DPIs, he/she would be randomly assigned to one of the inhaler groups. The data are presented as numbers (percentages), median (Lower quartile, Upper quartile), mean \pm standard deviation (SD). KruskalWallis test was used to calculate the distribution of daily PIFs of different DPIs and the distribution of the number 
of manipulation errors. Chi-square test examined whether there are significant differences in the PIF status and operation status of patients with COPD, asthma, and overlap. Associated factors of suboptimal PIF/technique misuse were investigated by univariate analysis (SI Methods) and subsequently entered into logistic regression analyses. All analyses were performed using SPSS Windows version 21 SPSS software (IBM Corporation, Somers, NY, USA). Statistical significance was set as a two-sided p-value of 0.05 .

\section{Results}

\section{Patient Demographics}

A total of 85 patients were enrolled in this study (Table 2). All these patients had used one or more of the three DPIs (HAN, TUR, and DIS) for more than two weeks. The median age of the patients $(68 / 80.0 \%$ male and 17 female) was 67.0 years $[60.5,74.0]$. The median weight of the patients was $66.5 \mathrm{~kg}[55.0 ; 70.0]$. A total of $9(10.6 \%)$ patients had respiratory diseases, of which eight had lung cancer and one had pulmonary embolism. All patients have received treatment for their respiratory diseases and were in a stable state. Of the 85 included patients, 52 $(61.2 \%)$ were diagnosed with COPD, 22 (25.9\%) with asthma, and $11(12.9 \%)$ with ACO. The smoking status, distribution of education level, and $\mathrm{FEV}_{1} \%$ Predicted are listed in Table 2. The information of each disease subgroup is also listed in Table 2. There were 29 patients in the HAN group, 29 patients in the TUR group, and 27 patients in the DIS group.

\section{Measurement of Daily PIFs}

The number of patients with daily PIF suboptimal was 33 $(38.8 \%)$ of the overall population. The proportion of patients with a daily $\mathrm{PIF}<20 \mathrm{~L} / \mathrm{min}, 20-29 \mathrm{~L} / \mathrm{min}, 30-$ $59 \mathrm{~L} / \mathrm{min}, 60-89 \mathrm{~L} / \mathrm{min}, \geq 90 \mathrm{~L} / \mathrm{min}$ was $13.8 \%, 13.8 \%$, $72.4 \%, 0.0 \%, 0.0 \%$ for HAN, $0.0 \%, 0.0 \%, 48.3 \%$, $48.3 \%, 3.4 \%$ for TUR, and $0.0 \%, 0.0 \%, 40.7 \%, 51.9 \%$, $7.4 \%$ for DIS respectively (Figure 2). The result of Kruskal-Wallis test showed a significant difference in the distribution of the Daily PIFs among the three devices $(P<0.001)$, and further paired comparisons found a significant difference between HAN and TUR $(P<0.001)$, and HAN and DIS $(P<0.001)$.

Of the 85 patients, the number of patients with daily PIF below minimum was 4 (4.7\%). All four patients used HAN, and they reported that they did not notice the capsule rattle.
Of these four patients, two were diagnosed with COPD, one was diagnosed with asthma, and one was diagnosed with ACO. After the intervention of a pharmacist, the PIF of one COPD patient and one asthma patient could reach the standard. The other two patients never met the standard. One of them was a COPD patient, his CAT score was 10, and the $\mathrm{FEV}_{1} \%$ Predicted value is $62.2 \%$. After the intervention, he was hospitalized one month later because of the recurrence of cancer. The other patient was an ACO patient, and the $\mathrm{FEV}_{1} \%$ Predicted value was 39.93 .

\section{Misuse Rates for the Three Types of DPIs}

Of the 85 patients, the number of patients with technique misuse was $56(65.9 \%)$. The misuse rate for the three types of inhalers was $72.4 \%$ for HAN, $69.0 \%$ for TUR, and $55.6 \%$ for DIS. Table 3 presents the result of Kruskal-Wallis test which showed no significant difference in the distribution of the number of technique errors among the three DPIs. There was no difference in the distribution of the number of breathing-related technique errors among the three DPIs. However, there was a significant difference in the distribution of the number of non-breathing-related technique errors between HAN and TUR $(P<0.001)$, also DIS and TUR $(P<0.001)$.

For patients who used the HAN inhaler, the steps of the technique error were sorted according to the occurrence rate: 5) Breathe out not completely. 7) Without holding breath. 4) Fail to pierce button completely (Figure 3A). For patients who used the TUR inhaler, misuse steps are as follows: 4) Breathe out not completely. 2) Not hold the inhaler upright. 6) Without holding breath. 10) Not gargle after inhalation (Figure 3B). For patients who used the DIS inhaler, misuse steps are as follows: 3) Breathe out not completely. 5) Without holding breath. 9) Not gargle after inhalation (Figure 3C).

\section{Demographic and Clinical Measures Correlate of Suboptimal Daily PIF/ Technique Misuse}

Table 4 shows the overall usage of DPIs in overall and disease subgroups. There was no significant difference in the PIF and operation status of patients with COPD, asthma, and overlap. For overall patients, the results of the univariate analyses are shown in Tables S1-S8. Tables S1-S4 present the results of univariate analysis of the flow rate and demographic characteristics (age, sex, education level), cigarettes explosion (smoking years, smoking index), and clinical indicators (Weight, BMI, $\mathrm{FEV}_{1}, \mathrm{FEV}_{1} \%$ Predicted, 
Table 2 Demographical Characteristics and Clinical Data of the Patients

\begin{tabular}{|c|c|c|c|c|}
\hline Variables & Total $(n=85)$ & COPD $(n=52)$ & Asthma $(n=22)$ & $\operatorname{ACO}(n=I I)$ \\
\hline \multicolumn{5}{|l|}{ Demographics } \\
\hline Age $(y)$ & $67.0[60.5 ; 74.0]$ & $68.0[65.0 ; 75.8]$ & $58.0[45.0 ; 71.0]$ & $63.0[60.0 ; 67.0]$ \\
\hline Gender(\%male) & $68(80.0)$ & $49(94.2)$ & $8(36.4)$ & II (100.0) \\
\hline Weight (kg) & $66.5[55.0 ; 70.0]$ & $65.0[55.0 ; 70.0]$ & $67.0[60.0 ; 73.0]$ & $72.5[60.0 ; 78.0]$ \\
\hline Smoking (\%) & $65(76.5)$ & $49(94.2)$ & $2(9.1)$ & $10(90.9)$ \\
\hline Smoking Index & $600.0[2.0 ; 1000.0]$ & $800.0[510.0 ; 1200.0]$ & {$[0.0 ; 0.0]$} & $600.0[300.0 ; 800.0]$ \\
\hline With respiratory diseases (\%combined) & $9(10.6)$ & $7(13.5)$ & I (4.5) & $1(9.1)$ \\
\hline Education Level & $\mathrm{I}(\mathrm{I} .2)$ & I (I.9) & $0(0.0)$ & $0(0.0)$ \\
\hline Illiteracy & & & & \\
\hline Primary school & $16(18.8)$ & $10(19.2)$ & $5(22.7)$ & I (9.I) \\
\hline Junior high school & $30(35.3)$ & $22(42.3)$ & $5(22.7)$ & $3(27.3)$ \\
\hline High school & $13(15.3)$ & $8(15.4)$ & $2(9.1)$ & $3(27.3)$ \\
\hline University and above & $21(24.7)$ & $10(19.2)$ & $8(36.4)$ & $3(27.3)$ \\
\hline Missing value & $4(4.7)$ & I (I.9) & $2(9.1)$ & I (9.1) \\
\hline FEV,$\%$ Predicted & $59.5[33.1,77.8]$ & $57.6[31.7,72.9]$ & $86.5[67.9,92.7]$ & $45.4[33.0,52.2]$ \\
\hline CAT & & $13.0 \pm 7.4$ & & $14.0 \pm 5.1$ \\
\hline \multicolumn{5}{|l|}{ mMRC scale } \\
\hline $\mathbf{0}$ & & $8(15.4)$ & & $0(0.0)$ \\
\hline $\mathbf{I}$ & & $12(23.1)$ & & $5(45.5)$ \\
\hline 2 & & $16(30.8)$ & & $4(36.4)$ \\
\hline 3 & & $9(17.3)$ & & $2(18.2)$ \\
\hline 4 & & $7(13.5)$ & & $0(0.0)$ \\
\hline ACT & & & $21.0[19.0 ; 22.0]$ & \\
\hline $\begin{array}{l}\text { Received medication education before } \\
\text { Yes }\end{array}$ & $85(100)$ & $52(100)$ & $22(100)$ & II (100) \\
\hline \multicolumn{5}{|l|}{ Inhalation Type (after randomization" } \\
\hline Number of people using HAN & $29(34.1)$ & $18(34.6)$ & $7(3 \mid .8)$ & $4(36.4)$ \\
\hline Number of people using TUR & $29(34.1)$ & $19(35.8)$ & $10(47.6)$ & $0(0.0)$ \\
\hline Number of people using DIS & $27(31.8)$ & $15(28.3)$ & $5(23.8)$ & $7(63.6)$ \\
\hline
\end{tabular}

Notes: Data are presented as mean \pm SD or numbers (percentages), median [Lower quartile, Upper quartile]; ${ }^{\#}$ If a patient uses a DPI, the patient is included in the corresponding device group; If patients use two different DPIs, they will be randomly assigned to one of the device groups.

Abbreviations: ACO, asthma-COPD Overlap; BMI, body mass index; COPD, Chronic obstructive pulmonary disease; DPI, dry powder inhaler; HAN, HandiHaler ${ }^{\circledR}$; TUR, Turbuhaler ${ }^{\circledR}$; DIS, Diskus ${ }^{\circledR}$.

whether with respiratory disease, exhale completely) in overall patients. Univariate studies found significant differences in age, weight, combined with respiratory diseases or not among patients with optimal/suboptimal PIF. Enter age, weight, combined with respiratory diseases or not, and sex in logistic regression analysis and found that age was a risk factor for suboptimal daily PIF (OR $=1.06,95 \%$ CI 1.01 1.12). Combined with respiratory diseases was also a risk factor for suboptimal daily PIF (OR $=6.59,95 \%$ CI 1.14 38.15) (Table 5). Tables S5-S8 present the results of univariate analysis of the operation correctness and demographic characteristics, cigarettes explosion, and clinical indicators in overall patients, and no statistically significant factors were found. However, after entering age, sex, weight, combined with respiratory diseases or not and education level in logistic regression analysis, we found that education level was a protective factor for technique misuse; the higher the level, the lower the incidence of technique misuse (OR $=0.63,95 \%$ CI 0.40-0.99) (Table 6).

Tables S9-S12 present the results of univariate analysis of the flow rate and demographic characteristics (age, sex, living status, education level), cigarettes explosion 


\section{Daily PIFRs of patients with DPIs}

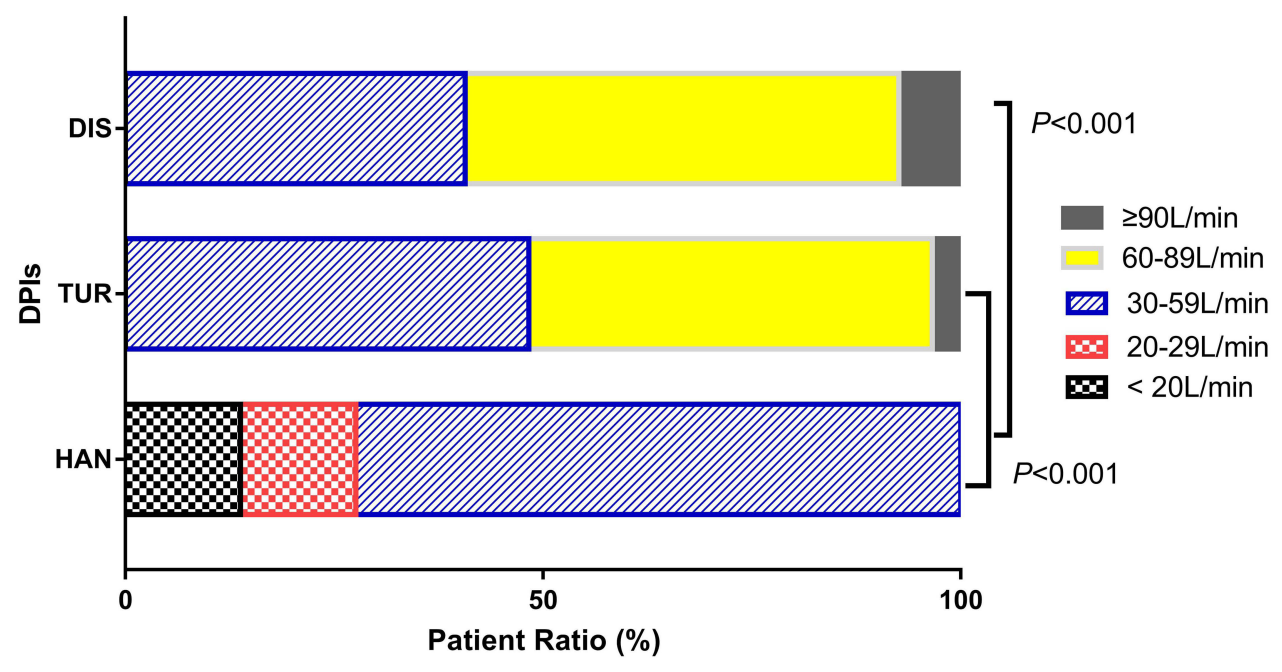

Figure 2 The daily PIFs distribution of DPIs.

Notes: Kruskal-Wallis test showed a significant difference in the distribution of the Daily PIFs among the three devices $(P<0.00 \mathrm{I})$, and further paired comparisons found a significant difference between HAN and TUR $(P<0.00 \mathrm{I})$, and HAN and DIS $(P<0.00 \mathrm{I})$.

Abbreviations: DPI, dry powder inhaler; HAN, HandiHaler ${ }^{\circledR}$; TUR, Turbuhaler ${ }^{\circledR}$; DIS, Diskus ${ }^{\circledR}$.

Table 3 The Distribution of the Number of Patients' Technique Error with Different DPIs

\begin{tabular}{|c|c|c|c|c|}
\hline & \multicolumn{3}{|c|}{ DPIs } & \multirow[t]{2}{*}{$P$-value } \\
\hline & HAN $(n=29)$ & TUR(n=29) & DIS (n=27) & \\
\hline \multicolumn{5}{|c|}{ The number of technique errors } \\
\hline 0 & $8(27.6)$ & $9(31.0)$ & $12(44.4)$ & 0.164 \\
\hline 1 & $9(31.0)$ & $4(13.8)$ & $5(18.5)$ & \\
\hline 2 & $10(34.5)$ & 7 (24.I) & $8(29.6)$ & \\
\hline 3 & $2(6.9)$ & $5(17.2)$ & $2(7.4)$ & \\
\hline 4 & $0(0.0)$ & $4(13.8)$ & $0(0.0)$ & \\
\hline \multicolumn{5}{|c|}{ The number of breathing-related steps errors } \\
\hline 0 & $8(27.6)$ & II (37.9) & $13(48.1)$ & 0.244 \\
\hline 1 & II (37.9) & $12(41.4)$ & $8(29.6)$ & \\
\hline 2 & $9(31.0)$ & $6(20.7)$ & $6(22.2)$ & \\
\hline 3 & I (3.4) & $0(0.0)$ & $0(0.0)$ & \\
\hline \multicolumn{5}{|c|}{ The number of non-breathing-related steps errors } \\
\hline 0 & 26(89.7) & $13(44.8)$ & $21(77.8)$ & $<0.00 I^{*}$ \\
\hline I & $3(10.3)$ & $8(27.6)$ & $5(18.5)$ & \\
\hline 2 & $0(0.0)$ & $7(24.1)$ & I (3.7) & \\
\hline 3 & $0(0.0)$ & I (3.4) & $0(0.0)$ & \\
\hline
\end{tabular}

Notes: Data are presented as numbers (percentages); Performed by KruskalWallis test; *There was a significant difference in the distribution of the number of non-breathing-related steps errors among the three devices $(P<0.00 \mathrm{I})$, and further paired comparisons found that significant difference between HAN and TUR $(P<0.001)$, and HAN and DIS $(P<0.001)$.

Abbreviations: DPI, Dry Powder Inhaler; HAN, HandiHaler ${ }^{\circledR}$; TUR, Turbuhaler ${ }^{\circledR}$; DIS, Diskus ${ }^{\circledR}$. (smoking years, smoking index), and clinical indicators (the total number of exacerbations, number of moderate to severe exacerbations, number of severe exacerbations, CAT, $\mathrm{FEV}_{1} \%$ Predicted, Weight, BMI, whether with respiratory disease, grading of the number of acute exacerbations, mMRC, whether exhale completely) in COPD patients. There was no significant difference in these variables between optimal and suboptimal PIF groups. Enter age, weight, combined with respiratory diseases or not, and sex in logistic regression analysis, and no variables were included. Tables S13-S16 present the results of univariate analysis of the operation correctness and demographic characteristics, cigarettes explosion, and clinical indicators in COPD patients, and no statistically significant factors were found. Enter age, sex, weight, combined with respiratory diseases or not, and education level in logistic regression analysis, and no statistically significant factors were found. For asthma patients, Tables S17-S20 presents the results of univariate analysis flow rate and demographic characteristics (age, sex, living status, education level), cigarettes explosion (smoking years, smoking index), and clinical indicators (ACT score, $\mathrm{FEV}_{1}$, Weight, BMI, PEF, whether with respiratory disease, degree of asthma control, whether exhale completely). There was a statistically significant 
A

HAN

11. Clean the device once a month and dry it completely-

10. Tip out the used capsule and throw it away -

9. Repeat the inhalation

8. Breathe normally after holding breath

7. Hold your breath

5. Breathe out completely

4. Press the piercing button completely 3. Close the mouthpiece firmly until hear a click

2. Place the capsule in the center chamber

1. Open the dust cap and keep it upwards

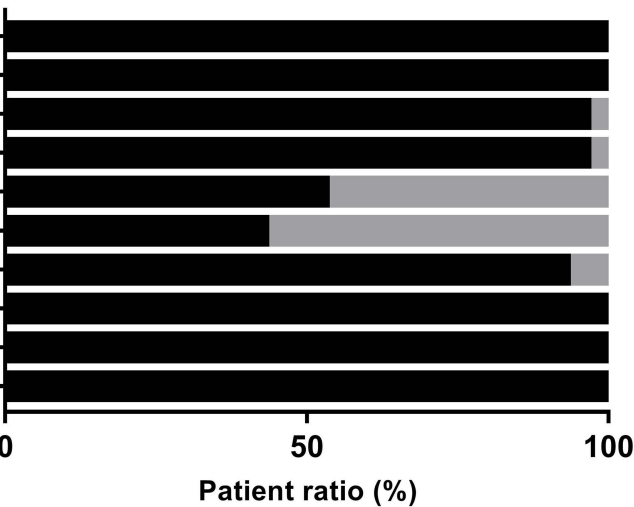

B

TUR

12. Keep the medicine in a dry place -

11. Know how to judge the remaining dose 10. Gargle after inhaling ICS-containing drugs

9. Separate the two doses for 30 s (if needed) 8. Close the cover

7. Breathe normally after holding breath

6. Hold breath

4. Breathe out completely

3. Turn the grip right and left until it clicks -

2. Hold the inhaler upright

1. Twist and remove the cover



C

DIS

11. Keep the medicine in a dry place

10. Know how to judge the remaining dose

9. Gargle after inhaling ICS-containing drugs

8. Separate the two doses for 30 s (if needed)

7. Close the cover

6. Breathe normally after holding breath

5. Hold breath

3. Breathe out completely

2. Pull down the slide

1. Open the cover

Wrong

Correct

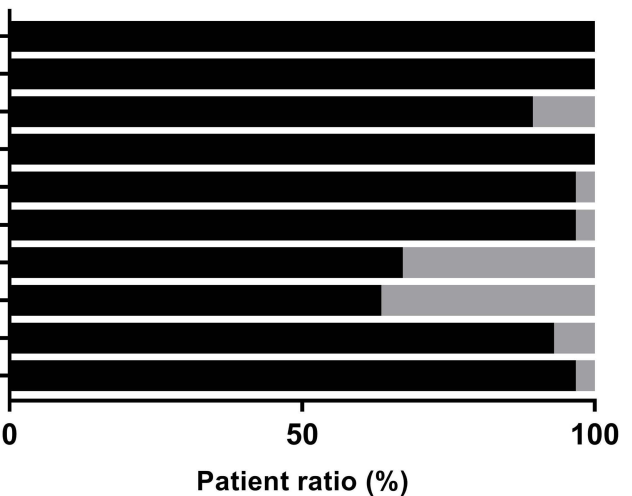

Figure 3 The proportion of correct and wrong steps. (A) Patients' technique of each step of HAN. (B) Patients' technique of each step of TUR. (C) Patients' technique of each step of DIS.

Notes: The step of "fast and deep inhalation" (the sixth step of HAN, the fifth step of TUR and the fourth step of DIS) was not evaluated, but the measurement of PIF was used to evaluate it.

Abbreviations: HAN, HandiHaler ${ }^{\circledR}$; TUR, $^{\text {Turbuhaler }}{ }^{\circledR}$; DIS, Diskus ${ }^{\circledR}$.

difference in age between PIF optimal and suboptimal group ( $P=0.027)$. Enter age, weight, combined with respiratory diseases or not and sex in logistic regression analysis and age was a statistically significant variable $(\mathrm{OR}=1.16$, 95\% CI 1.00-1.35) (Table S21). Tables S22-S25 present the results of univariate analysis of the operation correctness 
Table 4 The Correctness of Use DPIs in Overall and Disease Subgroups

\begin{tabular}{|c|c|c|c|c|c|c|}
\hline Variables & Total $(n=85)$ & COPD $(n=52)$ & Asthma $(n=22)$ & $\operatorname{ACO}(n=I I)$ & $\chi^{2}$ & $P$ \\
\hline \multicolumn{7}{|c|}{ PIF above the minimum } \\
\hline Yes & $81(95.3)$ & $50(96.2)$ & $21(95.5)$ & $10(90.9)$ & $1.220^{\mathrm{a}}$ & 0.760 \\
\hline No & $4(4.7)$ & $2(3.8)$ & $\mathrm{I}(4.5)$ & I (9.1) & & \\
\hline \multicolumn{7}{|c|}{ PIF optimal } \\
\hline Yes & $52(61.2)$ & $29(55.8)$ & $14(63.6)$ & $9(81.8)$ & 2.670 & 0.263 \\
\hline No & $33(38.8)$ & $23(44.2)$ & $8(36.4)$ & $2(18.2)$ & & \\
\hline \multicolumn{7}{|c|}{ Correct technique } \\
\hline Yes & $29(34.1)$ & $14(26.9)$ & $10(45.5)$ & $5(45.5)$ & 3.084 & 0.214 \\
\hline No & $56(65.9)$ & $38(73.1)$ & $12(54.5)$ & $6(54.5)$ & & \\
\hline
\end{tabular}

Notes: Chi-square test examined whether there are significant differences in the PIF status and operation status of patients with COPD, asthma, and overlap; ${ }^{\mathrm{a}}$ Fisher's exact test.

Abbreviations: ACO, asthma-COPD Overlap; BMI, body mass index; COPD, Chronic obstructive pulmonary disease; PIF, peak flow rate.

and demographic characteristics, cigarettes explosion, and clinical indicators in asthma patients. There was no significant difference in these variables between correct use and incorrect use groups. Enter age, sex, weight, combined with respiratory diseases or not, and education level in logistic regression analysis, and no statistically significant factors were found.

\section{Discussion}

The present study elicited four main findings. First, this study measured daily PIFs. In the overall population, the rate of daily PIF below the minimum was $4.7 \%$ (4/85), and the rate of daily PIF suboptimal was $38.8 \%(33 / 85)$. Second, of the 85 patients, the number of patients with technique misuse was 56 (65.9). The misuse rate for the three types of inhalers was $72.4 \%$ for HAN, $69.0 \%$ for

Table 5 Logistic Regression Analysis of Demographic/Clinical Measures and the Suboptimal Daily PIF

\begin{tabular}{|l|c|c|c|c|}
\hline Variables & B & SE & OR (95\% CI) & $\boldsymbol{P}$ \\
\hline Age & 0.06 & 0.03 & $1.06(1.01-1.12)$ & $\mathbf{0 . 0 3 0}$ \\
\hline Weight & -0.02 & 0.02 & $0.98(0.94-1.02)$ & 0.319 \\
\hline $\begin{array}{l}\text { With respiratory } \\
\text { diseases }\end{array}$ & 1.89 & 0.90 & $6.59(1.14-38.15)$ & $\mathbf{0 . 0 3 5}$ \\
\hline Sex & -0.97 & 0.69 & $0.38(0.10-1.48)$ & 0.164 \\
\hline
\end{tabular}

Notes: Logistic regression analysis found that age was a risk factor for suboptimal daily PIF $(\mathrm{OR}=1.06,95 \% \mathrm{Cl} 1.0 \mathrm{I}-\mathrm{I} .12, \mathrm{P}=0.030)$. Combined with respiratory diseases was also a risk factor for suboptimal daily $\operatorname{PIF}(\mathrm{OR}=6.59,95 \% \mathrm{Cl}$ I.14-38.15, $\mathrm{P}=0.035$ ), indicated in bold.

Abbreviations: SE, standard errors; OR, odds ratios; $\mathrm{Cl}$, confidence interval.
TUR, and $55.6 \%$ for DIS. And the error steps mainly involved the breathing-related steps, which were not fully exhaling before inhaling the medicine, and not holding the breath after inhaling. Third, for non-breathing-related technique steps, the number of errors that occurred on TUR was significantly higher than that of the other two devices $(P<0.001)$. Finally, in the overall population, age and combined with respiratory diseases were risk factors for suboptimal daily PIF, OR values were 1.06 (95\% CI 1.01$1.12)$ and $6.59(95 \%$ CI $1.14-38.15)$ respectively. Education level was a protective factor for technique misuse; the higher the level, the lower the incidence of technique misuse ( $\mathrm{OR}=0.63,95 \%$ CI $0.40-0.99)$.

For each DPI, there is a minimum turbulent energy threshold for sufficient deaggregation to occur during an inhalation, ${ }^{10}$ and the turbulent energy required for each

Table 6 Logistic Regression Analysis of Demographic/Clinical Measures and the Technique Misuse

\begin{tabular}{|l|l|l|l|l|}
\hline Variables & B & SE & OR (95\% CI) & $\boldsymbol{P}$ \\
\hline Age & 0.03 & 0.02 & $1.03(0.99-1.07)$ & 0.189 \\
\hline Education level & -0.47 & 0.23 & $0.63(0.40-0.99)$ & $\mathbf{0 . 0 4 3}$ \\
\hline Sex & 0.51 & 0.65 & $1.67(0.47-5.95)$ & 0.429 \\
\hline Weight & 0.02 & 0.02 & $1.02(0.98-1.06)$ & 0.287 \\
\hline $\begin{array}{l}\text { With respiratory } \\
\text { diseases }\end{array}$ & 0.75 & 0.88 & $2.11(0.38-11.76)$ & 0.395 \\
\hline
\end{tabular}

Notes: Logistic regression analysis found that education level was a protective factor for technique misuse; the higher the level, the lower the incidence of technique misuse $(\mathrm{OR}=0.63,95 \% \mathrm{Cl} 0.40-0.99, \mathrm{P}=0.043)$, indicated in bold. Abbreviations: SE, standard errors; OR, odds ratios; $\mathrm{Cl}$, confidence interval. 
DPI was different. As the DPI is completely driven by the patient's active inhalation, and the process of inhaling the drug needs to overcome the internal resistance of the device. Therefore, the PIF of DPIs is of great significance to drug deposition. Refer to data from literature, ${ }^{11-16}$ we defined PIF as "below minimum" if his/her measured PIF below $20 \mathrm{~L} / \mathrm{min}$ for HAN, or below $30 \mathrm{~L} / \mathrm{min}$ for TUR or DIS. If PIF was below $30 \mathrm{~L} / \mathrm{min}$ for HAN, or below $60 \mathrm{~L} /$ min for TUR or DIS, we defined it as "suboptimal". After investigation, we found that all the conditions below the minimum PIF occurred on the HAN device. For this part of patients, a further question of whether they can hear the capsule turning while taking the medicine should be asked. Among the four patients whose flow rate was below minimum, two patients could improve PIF through intervention, indicating that the patients were capable of reaching the target, but did not master the correct inhalation method. The other two patients consistently failed and should be switched to other devices (eg MDI + Valved holding chamber or nebulizer). We also found that the incidence of suboptimal PIF was high. Suboptimal PIF might lead to a decrease in the rate of drug deposition, thereby affecting the efficacy of the drug. In the literature, suboptimal PIFs are associated with all-cause readmissions of $\mathrm{COPD},{ }^{17}$ and improved responsiveness to nebulized therapy. ${ }^{18}$ Therefore, for patients whose PIF was not in the ideal range, attention should be paid to the guidance of inhalation method and monitoring of efficacy. It was also found that daily PIFRs of patients using HAN were lower than that of the TUR and DIS $(P<0.001)$, which could be explained that one patient generates similar pressure drops on different DPI, as the HAN inhaler had higher resistance, the corresponding flow rate was lower. However, the low PIF of HAN did not mean that low PIF cannot deaggregate the dose. Because the turbulent energy provides de-aggregate energy, which is determined by both the flow rate and the resistance. ${ }^{19}$

The incidence of operation errors was very high. However, patients we investigated were not using inhaled drugs for the first time, but for some time. When they first prescribed this type of medicine, the medical staff gave an oral introduction to the medication method (without video). The lack of standard operating procedures during the first training might be one of the factors in the high incidence of errors. Studies have shown that even medical staffs were lack knowledge and operating skills when dealing with inhalers. ${ }^{20-23}$ Therefore, medical staffs need to improve their knowledge and skills and strengthen standardized operation training for patients. ${ }^{24}$ The high incidence of operation errors in breathing-related steps suggests that the focus of inhaler technique training should be the use of correct inhalation manoeuvre. ${ }^{25}$ Exhale to residual volume (RV) ensured to inhale the maximum lung volume. $^{20}$ Held breath after inhalation increased drug deposition in the lung. ${ }^{26}$ Therefore, medical staff should strengthen the training of patients' breathing-related steps to help patients understand the importance of exhalation and breath-holding.

In the study, we found that the number of nonrespiratory-related operating errors of the TUR was higher than that of the other two devices, and the difference was statistically significant. DPIs contain different types with unique mechanics, which may lead to device-dependent technical errors. Because the drug application procedure of the TUR was relatively complicated, some elderly people did not understand the principle of the procedure, and the grip may be turned repeatedly, causing a waste of medicine. Therefore, our center should pay more attention to the training of non-breathing-related technique steps of the TUR.

Through logistic regression, we found that age was a risk factor for suboptimal daily PIF $(\mathrm{OR}=1.06,95 \%$ CI 1.01-1.12). Combined with respiratory diseases was also a risk factor for suboptimal daily PIF $(\mathrm{OR}=6.59$, 95\% CI 1.14-38.15). Elderly or combined with respiratory diseases, such as lung cancer, may lead to a decrease in the strength of the patient's respiratory muscles, resulting in decreased maximum inspiratory mouth pressure (MIP) and also suboptimal PIF. ${ }^{27}$ This was consistent with the reported in the literature that young children with asthma and elderly patients with COPD may lack the ability to generate sufficient flows (pressures) to correctly operate a DPI. ${ }^{28,29}$ We also found that education level was a protective factor for technique misuse; the higher the level, the lower the incidence of technique misuse (OR = $0.63,95 \%$ CI $0.40-0.99$ ). This was consistent with the literature report. ${ }^{30,31}$ It reminds us that we need to strengthen the training and evaluation of operation procedures for patients with a low level of education. In the asthma subgroup, we found that age was also a risk factor for suboptimal PIF (OR=1.16, 95\% CI 1.00-1.35).

Although our patients had received medication instructions from medical staff before our research, the incidence of suboptimal PIF was high. One possible reason was that 
patients did not have been measured PIF before and did not have a quantitative concept about PIFs. Also, they might forget the "deep and fast" inhalation method in their follow-up treatment. The PIF is rarely measured in clinical practice in China, although its significance has been emphasized in the related literature. ${ }^{3}$ Therefore, our cross-sectional investigation of the daily PIF in a Chinese hospital has a certain significance. As we investigated the daily inhalation method of the patients in the real world, the patients were required to simulate the inhalation method used at home and measured the daily PIF, ${ }^{32}$ and therefore our results could reflect the true situation of patient medication. This is different from the most research method reported in the literature, where the PIF was measured by requiring the patient to use the maximum inspiratory force. Moreover, the latest research shows that there are about 99.9 million people in China suffering from $\mathrm{COPD}^{33}$ and about 45.7 million Chinese adults suffering from asthma. ${ }^{34}$ Therefore, the user population of inhalers is very wide in China. The three DPI devices we studied are representative. On the one hand, the resistance of the three devices is high, medium, and med-low respectively. On the other hand, the sales of corresponding drugs in China are very large. Occupy the top three in the DPI market. $^{35}$

The present study had several limitations. First, this was a single-center study with a small number of people. We need to expand the sample size and the observation time. Second, Using In-Check Dial to evaluate the minimum flow rate and appropriate flow rate of each DPI may have limits. Because the flow rate and the medication deposition amount are a continuous change relationship, not like a "switch" where there is a strict threshold. We refer to the literature's recommendations for flow rate, but in clinical applications, we should take a cautious attitude towards the results. Third, due to the limitation of the instrument, we did not measure the inspiratory volume, inspiratory acceleration, and breath-holding time, which are also very important for drug deposition. We will add them in our future study. Finally, each medical staff does not adopt a unified standard when guiding patients to use drugs before. In future clinical practice, we should strengthen the training and education of medical staff.

\section{Conclusion}

Despite the use of DPIs and implementation of medication education, the patient's consistency of daily PIFs against the resistance of specific DPIs and the technique operation remain unoptimistic. Age and combination with respiratory diseases were risk factors for suboptimal daily PIF. Education level was a protective factor for technique misuse. The measurement of PIF can provide clear and easy-to-understand results for the evaluation of the inhalation method. The continuous evaluation of technique and PIFs of patients who have already used DPI is of great significance.

\section{Funding}

This work was supported by the following funding: Shanghai "Rising Stars of Medical Talent" Youth Development Program-Youth Medical Talents -Clinical Pharmacist Program; National Natural Science Foundation of China (No. 81670016); Military Construction Project of National Key Specialist-Clinical Pharmacy.

\section{Disclosure}

The authors have no conflicts of interest in this work.

\section{References}

1. Global strategy for asthma management and prevention. 2020. Available from: https://ginasthma.org. Accessed December 3, 2020.

2. Global initiative for chronic obstructive lung disease. 2021. Available from: https://goldcopd.org/2021-gold-reports/. Accessed December 3, 2020.

3. Ghosh S, Ohar JA, Drummond MB. Peak inspiratory flow rate in chronic obstructive pulmonary disease: implications for dry powder inhalers. J Aerosol Med Pulm Drug Deliv. 2017;30(6):381-387. doi:10.1089/jamp.2017.1416

4. Chen SY, Huang CK, Peng HC, Yu CJ, Chien JY. Inappropriate peak inspiratory flow rate with dry powder inhaler in chronic obstructive pulmonary disease. Sci Rep. 2020;10(1):7271. doi:10.1038/s41598020-64235-6

5. Westerik JA, Carter V, Chrystyn H, et al. Characteristics of patients making serious inhaler errors with a dry powder inhaler and association with asthma-related events in a primary care setting. J Asthma. 2016;53(3):321-329. doi:10.3109/02770903.2015.1099160

6. Li H, Chen Y, Zhang Z, Dong X, Zhang G, Zhang H. Handling of diskus dry powder inhaler in Chinese chronic obstructive pulmonary disease patients. J Aerosol Med Pulm Drug Deliv. 2014;27 (3):219-227. doi:10.1089/jamp.2012.1033

7. Zhang QL, Zheng JP, Pan WH, et al. [Peak inspiratory flow generated through different analogue dry powder inhalers in Shenzhen healthy preschool children]. Zhonghua Er Ke Za Zhi. 2008;46(2):98-103. [Chinese].

8. Sanders MJ. Guiding inspiratory flow: development of the in-check DIAL G16, a tool for improving inhaler technique. Pulm Med. 2017;2017:1495867. doi:10.1155/2017/1495867

9. The use of inhaler devices in adults. Uptodate, Inc; 2020.

10. Laube BL, Janssens HM, de Jongh FHC, et al. What the pulmonary specialist should know about the new inhalation therapies. Eur Respir J. 2011;37:1308-1331. doi:10.1183/09031936.00166410

11. Chodosh S, Flanders JS, Kesten S, Serby CW, Hochrainer D, Witek TJ. Effective delivery of particles with the HandiHaler dry powder inhalation system over a range of chronic obstructive pulmonary disease severity. J Aerosol Med. 2001;14(3):309-315. doi: $10.1089 / 089426801316970268$ 
12. de Boer AH, Bolhuis GK, Gjaltema D, Hagedoorn P. Inhalation characteristics and their effects on in vitro drug delivery from dry powder inhalers: part 3: the effect of flow increase rate (FIR) on the in vitro drug release from the Pulmicort 200 Turbuhaler. Int J Pharm. 1997;153(1):67-77. doi:10.1016/S0378-5173(97)00097-5

13. Borgstrom L, Bondesson E, Moren F, Trofast E, Newman SP. Lung deposition of budesonide inhaled via Turbuhaler: a comparison with terbutaline sulphate in normal subjects. Eur Respir J. 1994;7 (1):69-73. doi:10.1183/09031936.94.07010069

14. Hill LS, Slater AL. A comparison of the performance of two modern multidose dry powder asthma inhalers. Respir Med. 1998;92 (1):105-110. doi:10.1016/S0954-6111(98)90040-3

15. Al-Showair RA, Tarsin WY, Assi KH, Pearson SB, Chrystyn H. Can all patients with COPD use the correct inhalation flow with all inhalers and does training help? Respir Med. 2007;101 (11):2395-2401. doi:10.1016/j.rmed.2007.06.008

16. Janssens W, VandenBrande P, Hardeman E, et al. Inspiratory flow rates at different levels of resistance in elderly COPD patients. Eur Respir J. 2008;31(1):78-83. doi:10.1183/09031936.00024807

17. Loh CH, Peters SP, Lovings TM, Ohar JA. Suboptimal inspiratory flow rates are associated with chronic obstructive pulmonary disease and all-cause readmissions. Ann Am Thorac Soc. 2017;14 (8):1305-1311. doi:10.1513/AnnalsATS.201611-903OC

18. Mahler DA, Waterman LA, Ward J, Gifford AH. Comparison of dry powder versus nebulized beta-agonist in patients with COPD who have suboptimal peak inspiratory flow rate. J Aerosol Med Pulm Drug Deliv. 2014;27(2):103-109. doi:10.1089/jamp.2013.1038

19. de Boer AH, Hagedoorn P, Hoppentocht M, Buttini F, Grasmeijer F, Frijlink HW. Dry powder inhalation: past, present and future. Expert Opin Drug Deliv. 2017;14(4):499-512. doi:10.1080/ 17425247.2016.1224846

20. Self TH, Pinner NA, Sowell RS, Headley AS. Does it really matter what volume to exhale before using asthma inhalation devices? J Asthma. 2009;46(3):212-216. doi:10.1080/02770900802492087

21. Hanania NA, Wittman R, Kesten S, Chapman KR. Medical personnel's knowledge of and ability to use inhaling devices. Metered-dose inhalers, spacing chambers, and breath-actuated dry powder inhalers. Chest. 1994;105(1):111-116. doi:10.1378/chest.105.1.111

22. Chopra N, Oprescu N, Fask A, Oppenheimer J. Does introduction of new "easy to use" inhalational devices improve medical personnel's knowledge of their proper use? Ann Allergy Asthma Immunol. 2002;88(4):395-400. doi:10.1016/S1081-1206(10)62371-X

23. Kesten S, Zive K, Chapman KR. Pharmacist knowledge and ability to use inhaled medication delivery systems. Chest. 1993;104 (6):1737-1742. doi:10.1378/chest.104.6.1737
24. Capstick TG, Clifton IJ. Inhaler technique and training in people with chronic obstructive pulmonary disease and asthma. Expert Rev Respir Med. 2012;6(1):91-101. doi:10.1586/ers.11.89

25. Azouz W, Chrystyn H. Clarifying the dilemmas about inhalation techniques for dry powder inhalers: integrating science with clinical practice. Prim Care Respir J. 2012;21(2):208-213. doi:10.4104/ pcrj.2012.00010

26. Newman SP. Aerosol deposition considerations in inhalation therapy. Chest. 1985;88(2 Suppl):152S-160S. doi:10.1378/ chest.88.2_Supplement.152S

27. Clark AR, Weers JG, Dhand R. The confusing world of dry powder inhalers: it is all about inspiratory pressures, not inspiratory flow rates. J Aerosol Med Pulm Drug Deliv. 2020;33(1):1-11. doi:10.1089/jamp.2019.1556

28. Laube BL, Janssens HM, De jongh FHC, et al. What the pulmonary specialist should know about the new inhalation therapies. Eur Respir J. 2011;37:1308-1331.

29. Azouz W, Chetcuti P, Hosker HS, Saralaya D, Stephenson J, Chrystyn H. The inhalation characteristics of patients when they use different dry powder inhalers. J Aerosol Med Pulm Drug Deliv. 2015;28(1):35-42. doi:10.1089/jamp.2013.1119

30. Vitacca M, Paneroni M, Fracassi M, et al. Inhaler technique knowledge and skills before and after an educational program in obstructive respiratory disease patients: a real-life pilot study. Pulmonology. 2020. doi:10.1016/j.pulmoe.2020.04.010

31. Duarte-de-araujo A, Teixeira P, Hespanhol V, Correia-de-sousa J. COPD: misuse of inhaler devices in clinical practice. Int $J$ Chron Obstruct Pulmon Dis. 2019;14:1209-1217. doi:10.2147/COPD. S178040

32. Ghosh S, Pleasants RA, Ohar JA, Donohue JF, Drummond MB. Prevalence and factors associated with suboptimal peak inspiratory flow rates in COPD. Int $J$ Chron Obstruct Pulmon Dis. 2019;14:585-595. doi:10.2147/COPD.S195438

33. Wang C, Xu J, Yang L, et al. Prevalence and risk factors of chronic obstructive pulmonary disease in China (the China Pulmonary Health [CPH] study): a national cross-sectional study. Lancet. 2018;391 (10131):1706-1717. doi:10.1016/S0140-6736(18)30841-9

34. Huang K, Yang T, Xu J, et al. Prevalence, risk factors, and management of asthma in China: a national cross-sectional study. Lancet. 2019;394(10196):407-418. doi:10.1016/S0140-6736(19)31147-X

35. Wu Y, Cheng Y, You Y. Survey of inhalation use in 130 hospitals in 24 provinces and cities from 2011 to 2015 (in Chinese). Herald Med. 2017;36(12).

\section{Publish your work in this journal}

The International Journal of COPD is an international, peer-reviewed journal of therapeutics and pharmacology focusing on concise rapid reporting of clinical studies and reviews in COPD. Special focus is given to the pathophysiological processes underlying the disease, intervention programs, patient focused education, and self management protocols. This journal is indexed on PubMed Central, MedLine and CAS. The manuscript management system is completely online and includes a very quick and fair peer-review system, which is all easy to use. Visit http://www.dovepress.com/testimonials.php to read real quotes from published authors. 